REVIEW

\title{
Environmental toxins; their impact on children's health
}

\section{J Grigg}

Arch Dis Child 2004;89:244-250. doi: 10.1136/adc.2002.022202

Contamination of the environment by man-made and natural toxins has a direct impact on the health of children. This review considers how toxic contamination is identified and regulated, and highlights specific hazards.

declaration signed at a G8 summit (a meeting of the heads of state or government of the world's leading industrialised nations), which called for recognition of children's environmental health as a priority (table 2 ). In the same year, the US Environmental Protection Agency (EPA) established a policy to consider health risks to infants and children in all risk assessments, risk characterisations, and environmental standards. Furthermore, in 1998, the USA established a

Dr J Grigg, Senior Lecturer, Leicester Children's Asthma Centre, University of Leicester, ig33@le.ac.uk

Accepted 25 April 2003
.................. network of children's environmental health centres (table 3) to conduct multidisciplinary basic and applied research, as well as community based prevention research. ${ }^{4}$ The UK has several interlinked committees advising on environmental health (fig 1). Paediatric issues are not consistently reported separately by these committees, although age specific recommendations are included in some reports.

The second fundamental change in environmental risk assessment has been the adoption of the "precautionary principle". In the past, action tended to be taken only when a toxic environmental effect was clearly defined. By contrast, "the precautionary principle" accepts that scientific uncertainly is a fact of life, ${ }^{5}$ and is formalised in article 174 of the EU treaty. In practice, this means that when regulators are faced with uncertainty about a toxic (or other) environmental threat, they have a duty to respond and not wait until their worst fears are realised. In deciding exposure limits, they must err on the side of safety in the face of scientific uncertainly. An important consideration is the extent of a potential disaster to be avoided; thus more precautions should be applied to a threat affecting a whole population.

\section{VULNERABILITY OF CHILDREN}

The reasons why children should be considered separately are known to paediatricians, but not necessarily to scientists, politicians, and the general public. Children's diet differs from adults, and per unit kg body weight they consume more food and water, and breathe more air. Their immature organs are especially sensitive, and their external surfaces absorb

\section{CHILDREN'S ENVIRONMENTAL HEALTH}

Identifying, and prioritising which environmental contaminants impair children's health is a daunting task, not helped by duplication of efforts in scientific and regulatory committees between countries. However, two important advances have revolutionised how threats are assessed and contained. First, policy makers and scientists now accept that children are a particularly vulnerable group which deserve special and separate attention. A milestone was the 1997

oxic environmental hazards can be viewed
through several different constructs; devel-
oped versus developing world, occupational

Abbreviations: COT, UK Committee on the Toxicity of Chemicals; DEFRA, UK Department for Environment, Food and Rural Affairs; EPA, US Environmental Protection Agency; FSA, UK Food Standards Agency; MCCPs, medium chain length chlorinated paraffins; PCBs, polychlorinated biphenols; POPs, persistent organic pollutants; TEQ, international toxic equivalency factor; UF, uncertainty factor; UNEP, United National Environment Programme 
Table 1 Top six global burden of diseases associated with environmental exposure in children

\begin{tabular}{ll}
\hline Diseases & $\begin{array}{l}\text { Environmental fraction of } \\
\text { global burden (\%) }\end{array}$ \\
\hline Diarrhoeal diseases & 90 \\
Malaria & 90 \\
Acute respiratory infections & 60 \\
Chronic respiratory diseases & 50 \\
Unintentional injuries & 30 \\
Cancer & 25 \\
Overall environmental burden for all & 33 \\
diseases & \\
\hline \multirow{2}{*}{ 2002 data from the World Health Organisation.' }
\end{tabular}

more toxic material. Furthermore, the normal behaviour of infants and toddlers encourages ingestion of soils and floor dusts, and rapid growth increases the long term accumulation of chemicals. ${ }^{67}$ Although this review focuses on effects in children, end organ vulnerability may be greatest in the fetus and, for some compounds, toxic effects seen in childhood are the result of continuous exposure from conception. Few environmental exposures have been classified as "very likely" to be casual factors for birth defects, although many are "suspected possible/likely". ${ }^{8}$ Indeed epidemiological studies often reveal unexpected associations such as that between maternal herbicide exposure and arterial transposition. ${ }^{9}$ For children, high quality environmental toxicology data are rare, and developmental animal models are expensive. The wide range of variables that differentiate children from adults, and paucity of hard data, inevitably makes hazard identification, and limit setting for children a process of educated "pragmatic" guesses; and a situation ideally suited to a precautionary approach. An example of a pragmatic approach is the use of "uncertainty factors" (UF). In general, when a "no observed adverse effect level" (NOAEL) has been extrapolated from animal data, a further UF (for example, a 100-fold reduction in the NOAEL) is applied with the assumption that humans may be more sensitive..$^{10}$ In the USA, the increased vulnerability of children is explicitly recognised with an additional 10-fold UF for the fetus and infant.

\section{SPECIFIC HAZARDS}

One of the major concerns of governments is prioritising the assessment process-that is, dealing first with the most dangerous chemicals. The UK Advisory Committee on Hazardous Substances (fig 1), although not addressing children separately, is developing a safety net for chemicals of greatest concern, including those (1) with very great acute toxicity, (2) that are actually or potentially very bioaccumulative, (3) organic substances that may persist in the environment for decades, and (4) substances that may cause
Table 2 Key points of the 1997 declaration of the environmental ministers of the $\mathrm{G} 8$ on children's environmental health ${ }^{2}$

- Preventing exposure is the most effective way of protecting children's health from environmental threats

- National policies should take into account the specific exposure pathways and dose-response characteristics of children when conducting risk assessment and setting protective standards

- Research should be promoted to gain a better understanding of sensitivities of children to environmental hazards

- Awareness of the environments and health should be promoted to help families better protect their children

sublethal effects but may result in population level effects. ${ }^{11}$ Specific concerns about environmental pollutants and children's health broadly fall into these areas, with most concern about metals, and persistent organic pollutants (including pesticides). However, it is the unexpected sources of environmental contamination, such as the recent discovery of high levels of acrylamide in foods, ${ }^{12}$ that receive the most press attention and therefore are of most concern to parents.

\section{PERSISTENT ORGANIC POLLUTANTS}

Persistent organic pollutants (POPs) are carbon containing chemicals that are extremely stable, are transported over long distances, accumulate in high concentrations in fatty tissues, and are biomagnified through the food chain. They evaporate from warmer regions of the globe, and condense in the polar regions, thus posing a major threat to the Inuit population. Some POPs are pesticides, and nine of the most damaging (including DDT) are banned in Europe, in accordance with the 1998 Stockholm Convention on POPs. However, their persistence and accumulation within the food chain have resulted in widespread human exposures, especially from foods that are high in fat. Dioxins (polychlorinated-pdioxins), and polychlorinated-biphenols (PCBs) are examples of POPs that continue to be of concern. These two classes tend to be used interchangeably, since 12 of the 209 theoretically possible PCBs exhibit similar biological activity to dioxins, and are therefore called "dioxin-like PCBs". ${ }^{13}$ Dioxins are produced from thermal processes where chlorine is present. Although UK emissions of dioxins have fallen from 1178 grams in 1990, the National Atmospheric Emissions Inventory (table 3) shows that up to 354 grams per year are still being produced, with significant emissions from incinerators of clinical waste. ${ }^{14}$ PCBs were manufactured in large amounts until the 1970s, and were used in products that required thermal, chemical, and electrical stability (for example, wiring). Although the widespread use of PCBs is now banned, we are left with their legacy, with

Table 3 Environmental websites accessed December 2003

\begin{tabular}{ll}
\hline Name & Website \\
\hline UK Department for Environment, Food and Rural Affairs & http://www.defra.gov.uk \\
UK Food Standards Agency & http://www.foodstandards.gov.uk \\
UK National Atmospheric Emissions Inventory & http://www.airquality.co.uk \\
United Nations Environment Programme & http://www.unep.org \\
US children's environmental health centres & http://www.niehs.nih.gov/translat/children/ \\
& $\mathrm{ctr}-$ desc.htm \\
US Environmental Protection Agency & http://www.epa.gov \\
\hline
\end{tabular}




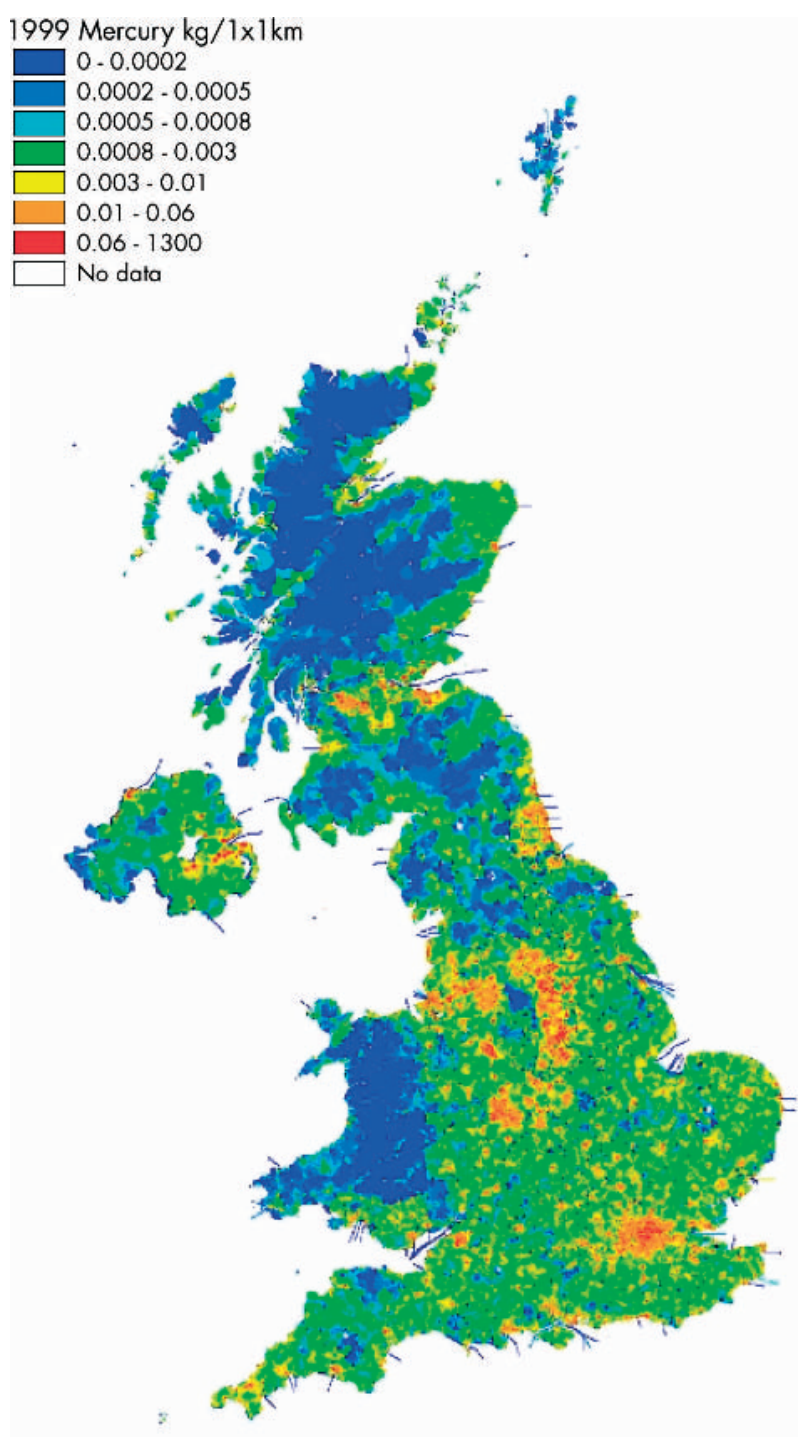

Figure 1 Emissions of mercury in the UK in 1999 including data within the 12 mile coastal limit.

release from historically contaminated landfills; an important source of $1706 \mathrm{~kg}$ of atmospheric PCBs in 2000. ${ }^{14}$

Because of biopersistence, children remain "actively" exposed to dioxins and PCBs, since they are present in foods (for example, meat, fish, egg) and breast milk. In 1994, dioxins and PCBs in human milk translated to an intake of 170 picograms International Toxic Equivalency Factors (TEQ) per kg body weight for a 2 month old child. The TEQ relates the toxicity of structurally related molecules to a reference molecule. This enables the calculation for overall toxicity when cocktails of similar chemicals (for example, in food) are ingested; for dioxins the reference molecule is 2,3,7,8-TCDD (tetrachlorodibenzo- $p$-dioxin). Paediatric exposure to dioxins has fallen significantly since the 1960s, but it remains impossible to predict when exposure of UK children will be under the recommended "tolerable" daily intake (amount in food or drinking water per body mass, which can be ingested daily over a lifetime by humans without appreciable health risk), of 2 pg TEQ/kg per day. ${ }^{13}$

What could these substances be doing to children's health? The adverse effects of dioxins are due to their binding to the aryl hydrocarbon receptor (AHR), which in turn influences a range of gene transcriptions. ${ }^{15}$ In reviewing the huge body of data on POPs, the UK Committee On the Toxicity of Chemicals (COT), adopted a commonly used approach. Conclusions were derived from "key studies" - identified by reviewing the strengths and weakness of all the relevant data; an approach analogous to the Scottish Intercollegiate Guideline approach for asthma therapies. ${ }^{16}$ Key animal studies showed effects on the developing reproductive systems of male rat fetuses exposed in utero, ${ }^{17}{ }^{18}$ and evidence of carcinogenicity. ${ }^{13}$ Epidemiological associations for humans included diabetes, and a change in sex ratio of offspring, but these studies were considered to contain a "high level of uncertainly". ${ }^{13}$ The committee's concern, however, focused on the data linking dioxin and children's neurocognitive development. For example, Koopman-Esseboom and colleagues $^{19}$ recruited a cohort of healthy Dutch infants and mothers and assessed PCB exposure. Children with increased PCB exposure exhibited a slight decrease in a neurodevelopment test at 7 months, ${ }^{19}$ and at follow up at 42 months. ${ }^{20}$ At 7 years, boys exposed to high levels of PCB exhibited less "masculine" play, and less "feminine" play was observed in girls. ${ }^{21}$ Looking at all the data, COT concluded that it was not possible to determine whether cognitive changes in children represented temporarily delayed milestones, or a persistent decrement. As for many of these evaluations, more data were requested, especially from follow up studies. ${ }^{13}$

To date, human data do not provide a sufficiently robust basis for establishing a tolerable intake, both for the general population, and for children as a potentially vulnerable subgroup. As more "esoteric" POPs come under scrutiny, there will be a further reduction of the available toxicological data. PCB and dioxin contamination is not going to disappear since old electrical equipment remains in the environment, and contamination incidents still occur, such as when a supplier in 1999 sold animal feed contaminated with industrial oil containing dioxins to Belgian farms. ${ }^{22} \mathrm{New}$ sources of contamination also appear. For example, exposure to sunlight turns triclosan, an ingredient of antibacterial soaps, into a dioxin. ${ }^{23}$ Reflecting continuing concerns, the UK government published a consultation document on the formation of a "Dioxins Action Plan" in 2002, and asked for suggestions on how to further reduce emissions from open burning, food contamination, and how to monitor and collect data on the extent of the problem. ${ }^{13}$

\section{LEAD}

The effect of lead on children's health is one of those most clearly understood in the environmental field, but a great deal of controversy remains on what is the "safe level". The effects of lead are related to the blood concentration, which confusingly is still expressed in non-SI units $(\mu \mathrm{g} / \mathrm{dl})$. Blood lead limits have decreased progressively from $60 \mu \mathrm{g} / \mathrm{dl}$ in the 1960s, and currently US and WHO guidelines recommend a maximum level of $10 \mu \mathrm{g} / \mathrm{dl} .{ }^{24}$ With the banning of lead additives in petrol, industrial emissions have become an important contributor to environmental contamination. For children, the primary route for lead is oral ingestion via food, water, soil, and dust. Once absorbed, lead follows the distribution of body calcium.

Children are especially sensitive to the toxic effects of lead, since compared with adults, more is absorbed via the gastrointestinal tract, a greater proportion of systemically circulating lead reaches the brain (especially under 5 years), and the developing nervous system is especially vulnerable to damage. $^{25}$ Lead neurotoxicity is predominately due to interactions with cellular mechanisms that normally perform calcium mediated functions..$^{25}$ Clinical lead poising in the UK is rare, but of 547 children aged 0-4 years during 1991-97, 
selected for suspicion of lead exposure, 45 had blood lead levels $>25 \mu \mathrm{g} / \mathrm{dl} .^{26}$

Classic paediatric studies have shown conclusive evidence of pre- and post-natal toxicity. For example, Bellinger and colleagues $^{27}$ showed that children whose cord blood lead levels were $>10 \mu \mathrm{g} / \mathrm{dl}$ had impaired cognitive development at 2 years, and Needleman and colleagues ${ }^{28}$ showed that increased lead levels were associated with a reduced IQ and increased non-adaptive classroom behaviour. The focus of the current debate is therefore whether there is any level of blood lead that has "no observed adverse effect" on neurodevelopment. In a recent review, Lidsky and Schneider ${ }^{25}$ concluded that (1) detrimental effects occur below $10 \mu \mathrm{g} / \mathrm{dl}$, and (2) the safe level of lead has not yet been identified. DEFRA has taken a similar precautionary view by stating that it is "prudent" to assume that lead's neurotoxicity exhibits no dose threshold, and exposure from soil contamination should be kept "as low as reasonably practicable". ${ }^{24}$ In the USA, where $10 \%$ of all children aged $1-5$ have blood levels $>4.8 \mu \mathrm{g} /$ $\mathrm{dl}$, and 430000 of these have levels $>10 \mu \mathrm{g} / \mathrm{dl},{ }^{29}$ lead exposure recommendations are a source of heated debate. In 2002, the Bush Administration rejected experts nominated for the Centers for Diseases Control and Prevention (CDC) lead evaluation committee. Rejected nominees had published literature that could be interpreted as showing the need for a lower limit for children's blood lead. For example, Dr Bruce Lanphear reported that at 5 years of age, IQ declines by 7.4 points as lifetime average blood lead concentration increases

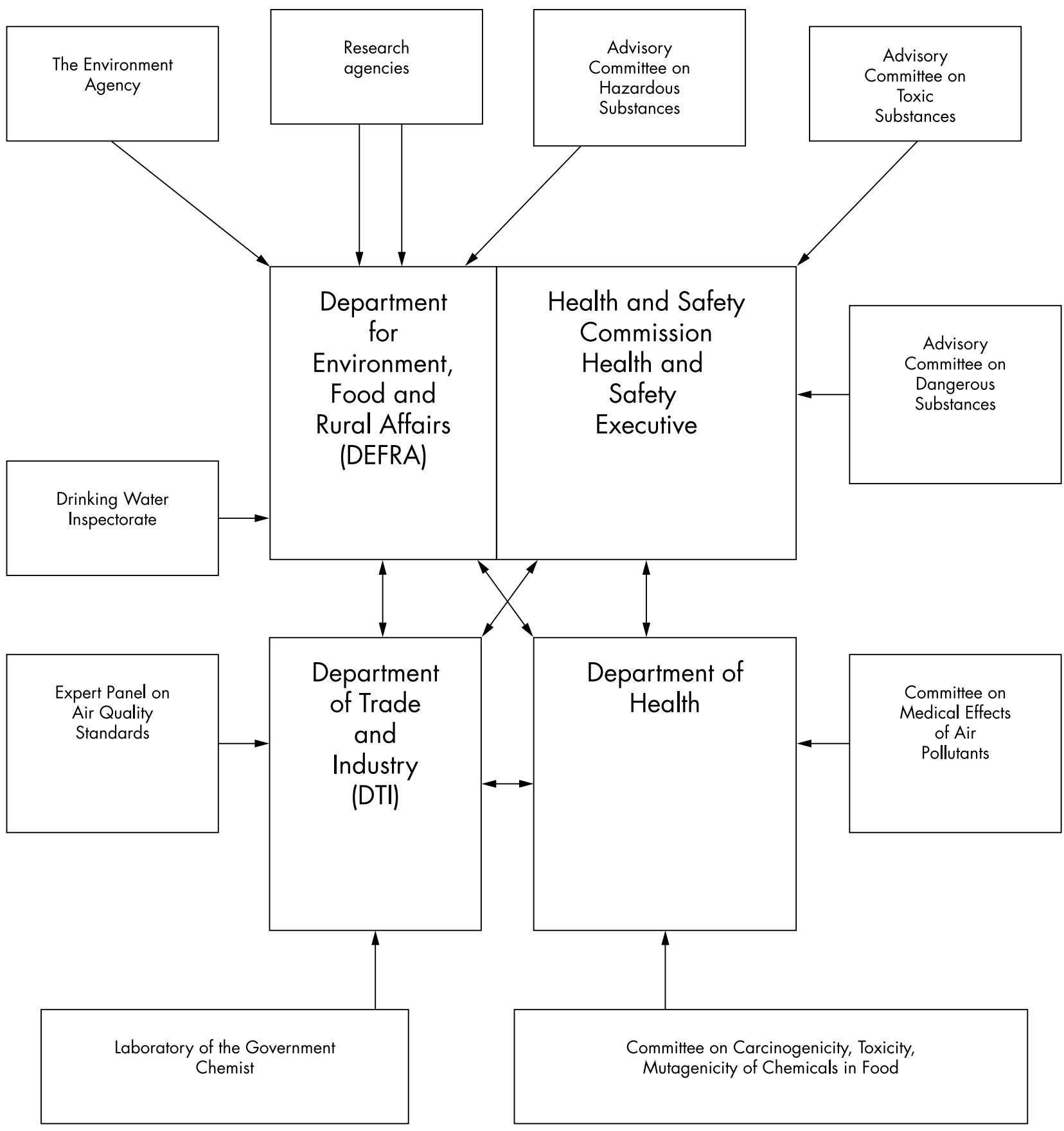

Figure 2 Main source of advice for the UK government on substances hazardous to human health and the environment. 
from 1 to $10 \mu \mathrm{g} / \mathrm{dl} .{ }^{30}{ }^{31}$ By contrast, administration nominated individuals were perceived by critics as having links with the lead industry. ${ }^{32}$

\section{MERCURY}

Mercury, like lead, is toxic to the developing brain. Important sources included coal fired power stations and waste incinerators. Mercury occurs in the Earth's crust, and natural sources include volcano emissions. ${ }^{33}$ Although natural sources do contribute significantly to atmospheric levels, man-made sources result in high local concentrations. In the UK, mercury emissions have declined by $80 \%$ since 1970, with the main sources now waste incineration, chlorine manufacturing, and coal combustion (fig 2). ${ }^{14}$ Methylmercury, the more toxic form, is produced by microorganisms acting on mercury in deposits in the sea and the soil. Since mercury accumulates through the food chain, the highest levels of methylmercury occur in predatory fish, which in turn is a major source of human exposure. ${ }^{34}$

Like lead, there remains vigorous debate on what, if anything, is a safe level of mercury exposure. The Minimata Bay incident (Japan) is the most widely known evidence of neurotoxicity, but more important from the regulatory point was contamination of Iraqi seed grain by a methylmercury containing fungicide in the 1970s. Neurodevelopmental effects in Iraqi children were similar to those in Japan with cerebral palsy, hyperrflexia, and impaired cognitive development. ${ }^{35}$ Since dose could be estimated from hair analysis, a safe exposure limit of $0.1 \mu \mathrm{g} / \mathrm{kg} /$ day was proposed by the US Environmental Protection Agency (EPA), even though the level set by the US Food and Drug Administration was much higher. ${ }^{36}$ The major problem in defending this safe limit is that two subsequent studies, with a more representative exposure than Iraq, came to differing conclusions. On the one hand, a study of a cohort of children in the Seychelles exposed when their mothers ate contaminated fish, found no association between maternal hair mercury and preschool neurodevelopmental outcome. ${ }^{37}$ On the other hand, Grandjean and colleagues, ${ }^{38}$ in the Faroe Islands, found an association between umbilical cord blood mercury (mean $22.9 \mu \mathrm{g} / \mathrm{l}$ ) and poorer neurocognitive performance at 8 years. Which one dataset should regulators choose? To answer this, the EPA set up an expert panel in 1998 with the National Academy of Sciences. Detailed analysis, and the addition of an unpublished data set from New Zealand, led the panel to conclude that the Faroe Islands study was the critical one for risk assessment purposes. ${ }^{39}$ This transparent process may help to redefine the way the quality of conflicting data is assessed in future.

In the UK, COT advice is that levels of mercury in the diet are "not a cause for toxicological concern" at the tolerable daily intake of $3.3 \mu \mathrm{g} / \mathrm{kg}$. Similarly, the parallel WHO international committee felt that they could not evaluate the risks for "subtle" neurological endpoints as used in the Faroe Islands study, that would be associated with lower intakes. ${ }^{34}$ But these positions may soon be re-evaluated. The global perspective on mercury is now different from that in Europe. The United Nations Environment Programme (UNEP), has drawn up a report which was presented in February 2003. In a BBC interview, Dr Klaus Töeper (UNEP director) said: "with another global health threat that especially affects children-lead in petrol-I am absolutely convinced we can reach an agreement to phase [the use of] mercury out worldwide" (http://news.bbc.co.uk/l/hi/sci/tech/ 2722629.stm). How far should elimination be taken, and how much data is required to justify changes that have major economic implications remains a challenge for governments. Hopefully these decisions will occur with the input from a public informed about the basics of risk assessment, and the precautionary principle.

\section{ASSESSING POTENTIAL NEW THREATS}

In 1995, Greenpeace conducted a study which apparently showed the presence of medium chain length chlorinated paraffins (MCCPs) in human breast milk. ${ }^{11}$ MCCPs are used to make a wide range of products including PVC plastics, paints, and leather goods. They are released into the environment (for example, into water) from manufacturing plants, and are thought to be absorbed by humans via water soil and food. ${ }^{11}$ The problems of evaluating the health threat from MCCPs, and the manner in which the threat was first identified, exemplify the wide range of information sources that regulators need to assimilate. To date, the only studies of MCCPs have been on fish and rats, which show toxicity at high doses. Even though the capacity of MCCPs to accumulate in humans and animals is unknown in the scientific literature, it was the potential for environmental persistence, and the provisional evidence of bioaccumulation, that rang alarm bells. In 2002, the Advisory Committee on Hazardous Substances took into account the limited toxicity studies and the Greenpeace data, and concluded that: (1) MCCPs do not occur naturally; and (2) there were no data on the likely effects on infants. ${ }^{11}$ However, MCCPs met the criteria for a "substance of greatest concern" when the committee took the precautionary approach-that is, it assumed that MCCPs were present in breast milk (even though these data were not published in a peer reviewed journal), and that they may affect health. In future, further bioaccumulative compounds will undoubtedly be discovered (currently the POP convention working group is considering pentaBDE, a brominated flame retardant, and endosulfan, a chlorinated hydrocarbon, as well as the chlorinated paraffins). An international breast milk monitoring programme would be one way of rapidly screening for chemical with biopersistence potential, ${ }^{40}$ but this has not yet been established. What we already know about breast milk contamination may indeed be the "tip of the iceberg", as environmental groups claim, ${ }^{41}$ but the absence of data could also mean that contamination is decreasing. What is clear is that toxicological assessment methodologies appropriate for "traditional" single compounds such as lead are inadequate for chemicals which may have hundreds of different congeners and enantiomers. ${ }^{42}$ Preventing these pollutant precursors from being produced by industry may therefore be the only approach that is likely to succeed.

\section{THE PAEDIATRIC VIEWPOINT}

Paediatricians can have an important part to play in children's environmental health. First, in the development of policy objectives, and placing into context potentially worrying reports. For example, chemical contamination of breast milk must not mean that mothers give up this vital nutrient for their children. Chemicals in breast milk highlight their potential for bioaccumulation, but not necessarily their toxicity to infants. Indeed, the alternatives of processed cows' milk and tap water, may impose the same, or even greater, burden. Second, paediatric input to UK regulatory committees will ensure that children's health is highlighted as a separate issue, which may in turn raise the awareness for paediatric research programmes to fill in gaps, such as the US "strategy for research on environmental risks to children". ${ }^{43}$ A useful first step would be the creation of a single UK information source summarising the paediatric output of the main government committees, which highlights both the certainties and the uncertainties. Third, at the individual level paediatricians could provide advice on reducing the toxicological burden to expectant mothers and children. Some 
interventions are readily apparent; exposure of children to the carcinogen 1,3-butadiene is reduced by avoiding passive exposure to cigarette smoke. ${ }^{44}$ For methylmercury, the UK recommendations are to include fish in a healthy diet, and only avoid shark, swordfish, and marlin if you are a women who aims to be pregnant (or who is pregnant), and not to give these fish to children. For PCBs, the UK Food Standards Agency (FSA) advises that "the potential negative effects to health come from long term exposure to high levels of PCBs and dioxins". For parents interested in avoiding PCBs, the advice is that "it is important to remember that the health benefits of eating one portion of oily fish a week as part of a healthy diet outweigh any potential threat from PCBs and dioxins" (table 3). However, the parental perspective may be subtly different from that of regulatory bodies. Parents interested in reducing the intake of toxins such as organophosphorous (OP), beyond the limits considered acceptable by regulators, by using the best preparation method, and avoiding foods from specific countries and still produce a balanced diet, will find it difficult to obtain unbiased advice. For pesticides the FSA states that "on the best science available, no harm will come to people who consume an amount of pesticide that is below the safety limits for that

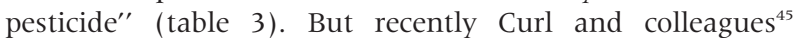
reported significantly less OP residues in US organic foods. Do UK organic foods also have less pesticide residues? If so, could this make a difference to health outcome if a precautionary view is taken by the parent? Does bottled water have less POPs and pesticide residues than tap water? Networks are being developed that may eventually provide appropriate information to paediatricians and parents, such as the EU supported International Network in Children's Health, Environment and Safety. This group aims to: (1) increase understanding on how environmental factors influence child health; (2) create an EU and worldwide clearing house of research and information on children's environmental health; (3) educate and facilitate information exchange on the best practice and policies; and (4) identify information gaps and stimulate new research. These goals could serve as a template for a UK initiative on children's environmental health.

In conclusion, normal children continue to be exposed to a range of environmental toxins. The evaluation of these potential threats to health is at the interface between scientific data evaluation, pragmatic decision making, governmental policy, and the concerns of the general public. Ideally, paediatricians, as advocates for children, should be engaged at all levels. One way of developing the WHO concept of "environmental justice" ${ }^{\text {"1 }}$ for children, would be the creation of a UK children's environmental health strategy. This could assess not only toxic threats, but also other issues such as designing environments that minimise accidental injuries and deaths in children.

\section{ACKNOWLEDGEMENTS}

The mercury emission map was provided by the UK Department for Environment, Food and Rural Affairs and Necten (AEA Technology Environment). I am grateful for the comments of Dr Sabine Kleinert.

\section{REFERENCES}

1 United Nations Environment Programme, United Nations Children's Fund, and World Health Organisation. Children in the new millennium. Environmental impact on health. United Nations, 2002:22.

2 Tamburlini G, von Ehrenstein OS, Bertollini R. Introduction. In: Tamburlini G, von Ehrenstein OS, Bertollini R, eds. Children's health and environment: a review of evidence. Copenhagen: European Environment Agency and the WHO Regional Office for Europe, 2002:12-15.

3 Grigg J. The health effects of fossil fuel derived particles. Arch Dis Child 2002;86:79-83.
4 Barrett JR. On a growth curve: children's environmental health centers. Environ Health Perspect 2002;1 10:A570-2.

5 Mayer B, Brown P, Linder M. Moving further upstream: from toxics reduction to the precautionary principle. Public Health Rep 2002:117:574-86.

6 Bearer CF. The special and unique vulnerability of children to environmental hazards. Neurotoxicology 2000;21:925-34.

7 Bearer CF. How are children different from adults? Environ Health Perspect 1995; 103(suppl 6):7-12.

8 Jensen TK. Birth defects. In: Tamburlini G, von Ehrenstein OS, Bertollini R, eds. Children's health and environment: a review of evidence. Copenhagen: European Environment Agency and the WHO Regional Office for Europe, 2002:99-112.

9 Loffredo CA, Silbergeld EK, Ferencz C, et al. Association of transposition of the great arteries in infants with maternal exposures to herbicides and rodenticides. Am J Epidemiol 2001;153:529-36.

10 Pease W, Vandenberg J, Hooper K. Comparing alternative approaches to establishing regulatory levels for reproductive toxicants: DBCP as a case study. Environ Health Perspect 1991;91:141-55.

11 Department for Environment, Food and Rural Affairs, Advisory Committee on Hazardous Substances. Sixth annual report. London: DEFRA Publications, 2003.

12 Stadler RH, Blank I, Varga N, et al. Acrylamide from Maillard reaction products. Nature 2002;419:449-50.

13 Department for Environment, Food and Rural Affairs, Scottish Executive, Welsh Assembly Government, and Northern Ireland Department of the Environment. Dioxins and dioxin-like PCBs in the UK environment. London: DEFRA Publications, 2002.

14 AEA Technology plc, for Department of the Environment, Transport and the Regions. National atmospheric emissions inventory 1970 to 1999. London: Department of the Environment, Transport and the Regions, 2000

15 Safe S. Molecular biology of the Ah receptor and its role in carcinogenesis. Toxicol Lett 2001;120:1-7.

16 Higgins BG, Douglas JG. The new BTS/SIGN asthma guidelines: where evidence leads the way. Thorax 2003:58:98-9.

17 Ohsako S, Miyabara Y, Nishimura N, et al. Maternal exposure to a low dose of 2,3,7,8-tetrachlorodibenzo-p-dioxin (TCDD) suppressed the development of reproductive organs of male rats: dose-dependent increase of mRNA levels of 5 alpha-reductase type 2 in contrast to decrease of androgen receptor in the pubertal ventral prostate. Toxicol Sci 200;60:132-43.

18 Mably TA, Bjerke DL, Moore RW, et al. In utero and lactational exposure of male rats to 2, 3, 7, 8-tetrachlorodibenzo-p-dioxin. 3. Effects on spermatogenesis and reproductive capability. Toxicol Appl Pharmacol 1992;114:118-26.

19 Koopman-Esseboom C, Weisglas-Kuperus N, de Ridder MA, et al. Effects of polychlorinated biphenyl/dioxin exposure and feeding type on infants' mental and psychomotor development. Pediatrics 1996;97:700-6.

20 Patandin S, Lanting Cl, Mulder PG, et al. Effects of environmental exposure to polychlorinated biphenyls and dioxins on cognitive abilities in Dutch children at 42 months of age. J Pediatr 1999;134:33-41.

21 Vreugdenhil HJ, Sliiper FM, Mulder PG, et al. Effects of perinatal exposure to PCBs and dioxins on play behavior in Dutch children at school age. Environ Health Perspect 2002;110:A593-8.

22 Bernard A, Fierens S. The Belgian PCB/dioxin incident: a critical review of health risks evaluations. Int J Toxicol 2002;21:333-40

23 Latch DE, Packer JL, Arnold WA, et al. Photochemical conversion of triclosan to 2,8-dichlorodibenzo-p-dioxin in aqueous solution. Photochemistry and Photobiology A: Chemistry 2003;158:63-6.

24 Department for Environment, Food and Rural Affairs and the Environment Agency. Contaminants in soil: collation of toxicological data and intake values for humans. Lead. Bristol: DEFRA Publications, 2002

25 Lidsky TI, Schneider JS. Lead neurotoxicity in children: basic mechanisms and clinical correlates. Brain 2003;126:5-19.

26 Elliott $P$, Arnold $R$, Barltrop $D$, et al. Clinical lead poisoning in England: an analysis of routine sources of data. Occup Environ Med 1999;56:820-4

27 Bellinger D, Leviton A, Waternaux C, et al. Longitudinal analyses of prenatal and postnatal lead exposure and early cognitive development. N Engl J Med 1987;316:1037-43.

28 Needleman HL, Gunnoe C, Leviton A, et al. Deficits in psychologic and classroom performance of children with elevated dentine lead levels. N Engl J Med 1979;300:689-95.

29 Woodruff TJ, Axelrad DA, Kyle AD, et al, eds. Body burdens: contaminants in the bodies of women and children. In: America's children and the environment. Measures of contaminants, body burdens, and illnesses. Washington: United States Environmental Protection Agency, 2003:51-90.

30 Lanphear BP, Dietrich K, Auinger $\mathrm{P}$, et al. Cognitive deficits associated with blood lead concentrations $<10$ microg/dL in US children and adolescents. Public Health Rep 2000;1 15:521-9.

31 Canfield RL, Henderson CR Jr, Cory-Slechta DA, et al. Intellectual impairment in children with blood lead concentrations below 10 microg per deciliter. N Engl J Med 2003;348:1517-26.

32 Ferber D. Toxicology. Overhaul of CDC panel revives lead safety debate. Science 2002;298:732

33 Tomiyasu T, Okada M, Imura R, et al. Vertical variations in the concentration of mercury in soils around Sakurajima Volcano, Southern Kyushu, Japan. Sci Total Environ 2003;304:221-30.

34 Department for Environment, Food and Rural Affairs and the Environment Agency. Contaminants in soil: Collation of toxicological data and intake value for humans. Mercury. London: DEFRA Publications, 2002. 
35 Kazantzis G, Al Mufti AW, Al Jawad A, et al. Epidemiology of organomercury poisoning in Iraq. II. Relationship of mercury levels in blood and hair to exposure and to clinical findings. Bull World Health Organ 1976;53(suppl):37-48.

36 Kaiser J. Mercury report backs strict rules. Science 2000;289:371-2.

37 Davidson PW, Myers GJ, Cox C, et al. Effects of prenatal and postnatal methylmercury exposure from fish consumption on neurodevelopment: outcomes at 66 months of age in the Seychelles Child Development Study. JAMA 1998;280:701-7.

38 Grandjean P, Weihe P, White RF, et al. Cognitive deficit in 7-year-old children with prenatal exposure to methylmercury. Neurotoxicol Terato 1997; 19:417-28

39 Jacobson JL. Contending with contradictory data in a risk assessment context: the case of methylmercury. Neurotoxicology 2001;22:667-75.

40 Hooper K, She J. Lessons from the polybrominated diphenyl ethers (PBDEs): precautionary principle, primary prevention, and the value of community-based body-burden monitoring using breast milk. Environ Health Perspect 2003;111:109-14.

41 Allsopp A, Santillo D, Johnston P, et al. The tip of the iceberg. State of knowledge on persistent organic pollutants in Europe and the Arctic. Greenpeace International Publications, 1999.

42 Howard CV. Synergistic effects of chemical mixtures-can we rely on traditional toxicology? The Ecologist 2003;1997:192-5.

43 United States Environmental Protection Agency, Office of Research and Development. Strategy for research on environmental risks to children. Washington, DC: EPA, 2000:1-38.

44 Expert Panel on Air Quality Standards. Second report on 1,3-butadiene. Department for Environment, Food and Rural Affairs, Scottish Executive, National Assembly for Wales, Department of the Environment in Northern Ireland, 2000.

45 Curl CL, Fenske RA, Elgethun K. Organophosphorous pesticide exposure of urban and suburban preschool children with organic and conventional diets. Environ Health Perspect 2003;111:1-6.

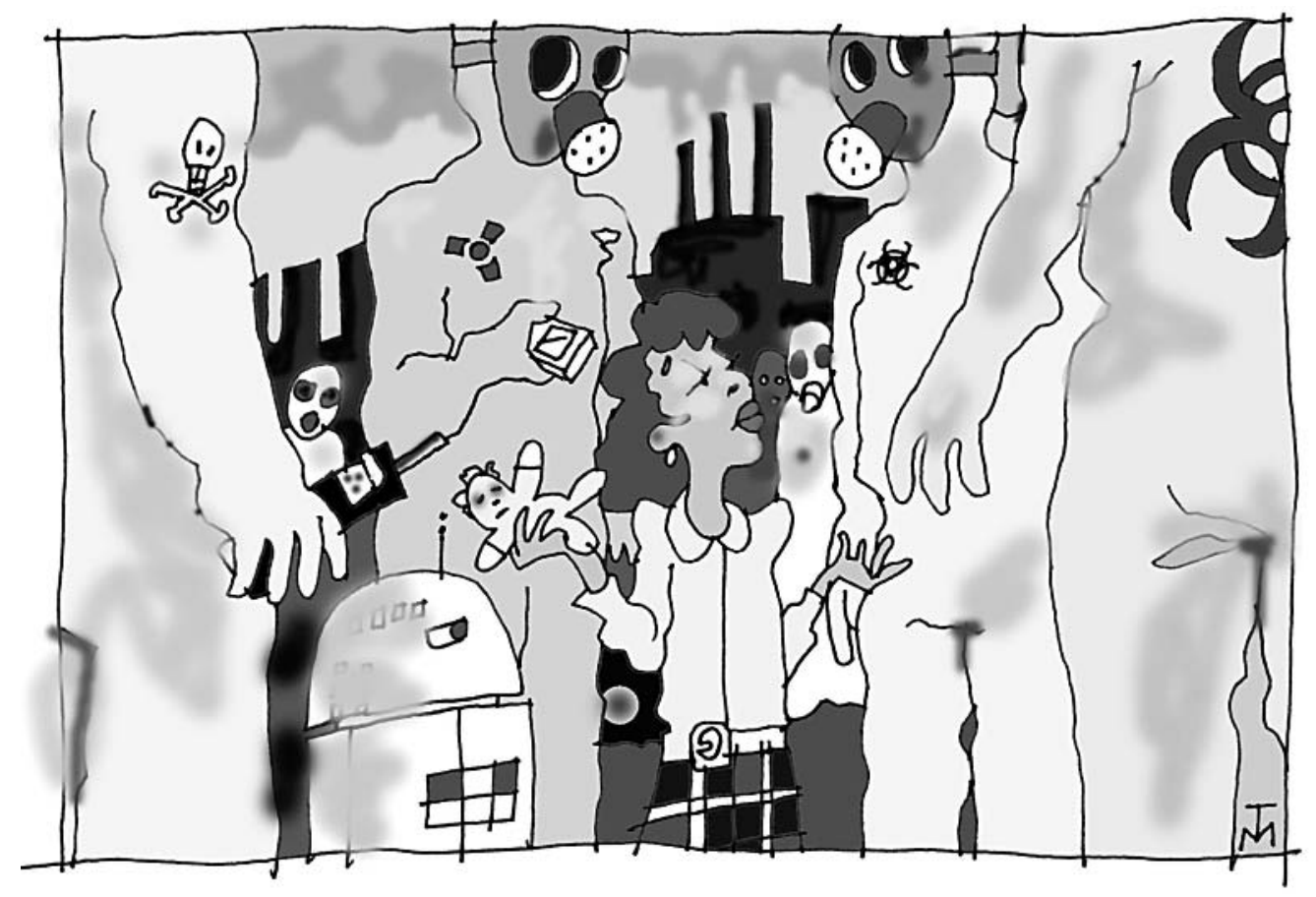

